\title{
When the Individual National Culture Meets a Transnational Research
}

\author{
Longjun Zhou, ${ }^{1,2}$ \\ 1. Jiangsu Second Normal University, Nanjing 211200, Jiangsu, China \\ 2. Engineering Research Center of Digital Learning Support Technology, Ministry of Education, Chang- \\ chun 130000, Jilin, China
}

"Research is formalized curiosity. It is poking and prying with a purpose"

-- Zora Neale Hurston

$\mathrm{W}$

HEN evidence enters humanities and society, with its scientific and effective characteristics, it gradually becomes a new paradigm for educational research and practice. It is becoming popular worldwide (Slavin, 2020). At present, all over the world, evidence-oriented evidence-based research has become one of the critical analysis methods in the educational research method system. Especially in the United States and the United Kingdom, evidence on the effectiveness of education reforms has become increasingly important, and more and more scholars are using evidence-based methods to study educational issues.

According to the definition of Whitehurst (2002), Assistant Secretary of the Office of Educational Research and Improvement, U.S. Department of Education, evidence-based education refers to "The integration of professional wisdom with the best available empirical evidence in making decisions about how to deliver instruction." Professional wisdom refers to the judgment acquired by an individual through experience. The experimental evidence comes from the scientific research results of psychology, neuroscience, sociology, economics, etc., especially the research results in the educational environment. This means that in evidence-based education, scientific evidence has an immeasurable role.

(C) 2021 Insights Publisher. All rights reserved.

(c) (i) (8) Creative Commons Non Commercial CC BY-NC: This article is distributed under the terms of the Creative Commons Attribution-NonCommercial 4.0 License

(http://www.creativecommons.org/licenses/by-nc/4.0/) which permits non-commercial use, reproduction and distribution of the work without further permission provided the original work is attributed by the Insights Publisher. 
The well-designed experiments, suitable experimental methods, and techniques advocated by evidence-based education emphasize logic, reasoning, and repeatability when analyzing data, making the research results of evidence-based education convincing. This has caused many researchers to pay more attention to the facts reflected in the data or evidence in the education reform when conducting educational experiments while ignoring the particular characteristics of education and eventually fell into the arrogance of evidence worship (Barends et al., 2014).

Education is a practice that revolves around people. It has mutual influence and interaction with political, economic, scientific and technological, and cultural factors (Davies, 1999). As Piaget (1988) said: "The public is not aware of the complexity of educational issues and does not know that pedagogy is a science comparable to other disciplines, and because of the complexity of various factors involved, This subject is even a complicated science."

In determining the evidence of educational intervention and educational practice, in addition to scientific characteristics and rigor, the appropriateness of the method is another crucial factor that education researchers must pay close attention to. In particular, the suitability of measurement tools is more critical. Only through scientific measurement tools and establishing a reasonable research norm can the essence of research be revealed.

In international comparative education research, using scientific measurement tools to conduct evidence-based research should arouse our attention. Due to the differences in cultural backgrounds, political systems, and concepts and habits of different countries, their perceptions of the same issue are diverse. This makes the answers of subjects in other countries to the same question not the same, which leads to differences in statistical results, and this difference cannot be used as compelling evidence for education evaluation. For example, in the assessment of collectivism, Westerners may give more negative comments, while Easterners may be more inclined to give positive responses (Yang, 2005).

Therefore, when doing transnational comparative research, we should localize measurement tools and conduct large-scale tests to establish a norm suitable for individual national research. Only by establishing measurement tools that are in line with the individual nation can it truly reflect the reality of education in the very individual country.

\section{References}

Barends, E., Rousseau, D.M., \& Briner, R.B. (2014). Evidence-Based Management, The Basic Principles. In Search of Evidence, Center for Evi- 
dence-Based Management.

https://www.academia.edu/download/62373957/_MEDICINA_BAZA

TA_PE_DOVEZI-complete_dissertation20200315-98085-

1gd9z63.pdf\#page=202

Davies, P. (1999). What is evidence-based education?. British Journal of Educational Studies, 47(2):108-121. DOI: https://doi.org/10.1111/1467$\underline{8527.00106}$

Piaget, J. (1988). Psychologie et pédagogie. Folio. ISBN: 978-2070324811. [French]

Slavin, R.E. (2020). How evidence-based reform will transform research and practice in education. Educational Psychologist, 2020, 55(1):21-31.

DOI: https://doi.org/10.1080/00461520.2019.1611432

Whitehurst, G.J. (2002). Evidence-based Education. http://ies.ed.gov/director/pdf/2002_10.pdf

Yang, N. (2005). Individualism-collectivism and work-family interfaces: A Sino-US comparison. In Steven A.Y. Poelmans, Work and family: An international research perspective, 3, 287-318. ISBN: 978-080-584882-3.

Correspondence to:

Longjun Zhou, Ph.D. Jiangsu Second Normal University

Nanjing 211200, Jiangsu

China

And

Engineering Research Center of Digital Learning Support Technology Ministry of Education, Changchun 130000, Jilin

China

Email: 294437034@qq.com

Conflict of Interests: None.

Doi: 10.15354/sief.21.ps011 